
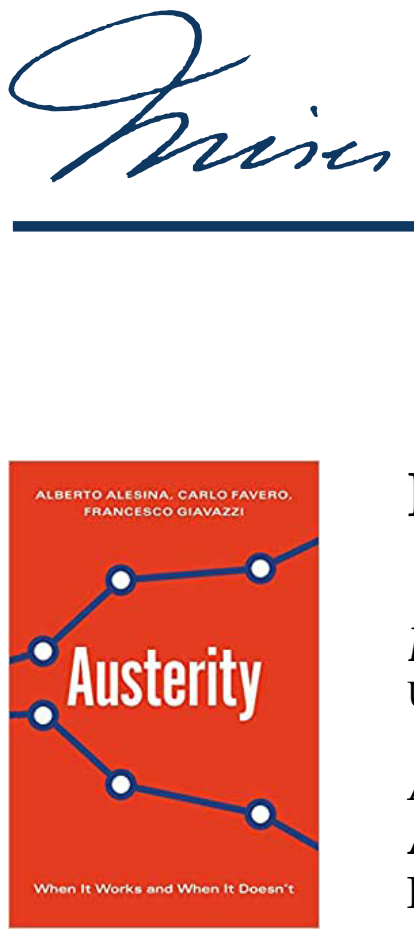

\title{
Faces of Austerity
}

Ludwig Van Den Hauwe ${ }^{\mathrm{I}}$ (100000-0002-4352-8003

Universidad Rey Juan Carlos, Madrid, Spain

ALBERTO, Alesina; FAVERO, Carlo; GIAVAZZI, Francesco.

Austerity - When It Works and When It Doesn't. Princeton:

Princeton University Press, 2019.

Discussions about the relative benefits and costs of the austerity politics implemented, following the financial crisis that started in 2007 , have mostly taken a very ideological and unproductive tone. The popular debate has been long on ideology and short on facts and details. The book under review comes at a very timely moment and sets the record straight in several respects. The basic Keynesian message had always been that spending cuts are more recessionary than tax increases. The most important contribution of the book consists in a demonstration, based on a very extensive documentation focusing on OECD countries, that this is not the case. The authors of the book uncover a very large difference in the output effect of expenditure-based (EB) austerity plans versus tax-based (TB) ones. However, whereas tax based plans lead to deep and prolonged recessions, lasting several years, expenditure-based plans on average exhaust their very mild recessionary effect within two years after a plan is introduced. EB austerity achieves the desired goal of reducing the growth rate of the debt over GDP ratio relative to what would have happened absent the austerity plan. On the contrary, in most cases, owing to the fall in the denominator, TB austerity plans are associated with an acceleration in the growth of the debt over GDP ratio.

The book comprises 11 Chapters. Chapter 2 reviews the basic "theory" of fiscal policy and sets out to introduce the reader to the highly complicated character of studying the effects of austerity. The authors start with the simple Keynesian theory and then, add a number of elements including incentives and supply-side effects, expectations, tax distortions and the

\footnotetext{
${ }^{\mathrm{I}}$ Ludwig Van Den Hauwe is an economist working in the tradition of the Austrian School of Economics. He pursues research on the applications of artificial intelligence at Universidad Rey Juan Carlos in Vicálvaro, Madrid, Spain. E-mail: ludwigvandenhauwe@gmail.com
} 
role of various possible accompanying policies. The aim of Chapter 3 is twofold. The first aim is to provide a few concrete examples of the main results, namely the different effects of tax-based and expenditure-based austerity and the possibility of austerity at very low or no cost (at least in terms of output losses). Several case studies of austerity plans, implemented before the financial crisis are described, distinguishing, broadly speaking, between examples of "expansionary austerity" on the one hand (comprising notable examples Belgium in the 1980s and Spain in the 1990s) and of "recessionary austerity", on the other hand. The second aim is to serve as a motivation to go more deeply into the data, by highlighting the many moving parts involved in determining the effects of austerity. Simple conclusions should be considered cautiously. Chapter 4 reviews previous econometric evidence on the effects of austerity and the related empirical evidence on "fiscal multipliers". Disagreements among economists on the size and sometimes even the sign of these "fiscal multipliers" persist.

The interaction between fiscal policy and output growth poses a so-called "endogeneity" problem. The authors address this problem by considering only policy changes motivated, not by the state of the business cycle, but only by a desire to reduce deficits. To that end, they use a novel approach to identifying episodes of changes in fiscal stance, which are not motivated by the state of the economic cycle, which has been labeled narrative identification, which contrasts, in this respect, with the early literature, which suffered from the imperfect identification of truly exogenous shifts in fiscal variables. This issue is further considered in Chapter 5, that contemplates the authors' main methodological innovation, the notion of fiscal plans. Austerity measures are typically implemented through multiyear policy packages and the authors' use of multiyear plans to study the effects of fiscal policy constitutes a crucial departure from the earlier literature. Chapter 6 which describes the construction of the data, providing a link to other researchers along with all the replication packages.

Chapter 7 presents the authors' main results on the effects of expenditure-based and taxbased austerity plans. Effects on GDP and its components - consumption, investment and net exports - but also on consumers' and business confidence and on interest rates are discussed. The component of aggregate demand, that responds very distinctly in the two types of plans is private investment. In fact, investors' confidence (which reflects their expectations about the future) reacts positively to EB plans and negatively to TB ones. Consumers' confidence moves in the same general direction, but with a smaller difference between the types of plans. That confidence effect is likely to be much smaller for tax plans and it is not difficult to understand. Because tax hikes do not address the automatic growth of entitlements and other spending programs that grow over time, they are much less likely to produce a long-lasting effect on the budget. If the automatic increase of spending is not addressed, taxes will have to keep rising to cover the increase in outlays. The result is that taxes will need to be constantly increased to cover the increase in outlays. Thus, the confidence effect is likely to be much smaller for tax hikes, as expectations of future taxes will continue to rise. Spending cuts produce the opposite effects. These results are very robust and they can neither be explained by different responses of monetary policy to different type of plans, nor by exchange rate movements. In cases where fiscal consolidation plans are accompanied by structural reforms - such as 
labor or goods market liberalization -- no evidence is found that it is the occurrence of these reforms that explains the different effects of EB and TB plans.

Chapter 8 focuses on the recent round of austerity plans implemented after the financial crisis. The major difference in the effects of spending cuts relative to tax increases is confirmed. No convincing evidence is found that multipliers were significantly larger in recent years. One of the reasons why the post-crisis austerity in Europe might have been especially costly is that it started when the economies were still in a deep recession. Motivated by this observation, Chapter 9 examines what difference it makes if an austerity plan is introduced at a time when the economy is growing rather than during a recession. The effect of "When" austerity occurs is hard to assess and this issue deserves further research. What are the electoral consequences of austerity?

In Chapter 10, it is shown that there is much less support than most people assume for the view that deficit reduction policies have negative electoral consequences. This does not mean that voters like austerity, but more simply that, in some places, they might understand the necessity of it and, when implemented appropriately, they may reward the incumbency for it, or at least not punish him or her. This is without any doubt one of the most important contributions of the book. The conventional wisdom has indeed been that, insofar as the rulers have a short-term decision horizon - mainly the horizon of the next elections - they are encouraged to distribute resources in the present, but to leave the burden of the corresponding payment to the voters of their successors. However, the evidence seems consistent with the view that voters sometimes understand the necessity of deficit reduction policies. The authors also find that, in general, governments implement austerity measures early in their term of office; that right-of-center governments are more likely to cut deficits; and that coalition governments are slower in implementing fiscal adjustments.

Chapter 11 summarizes the conclusions. The more technical aspects are illustrated in Chapter 12. Among other things, this chapter contains a general equilibrium model that allows to analyze the differences in effects between TB and EB austerity on the interactions of demand and supply. A critical factor that explains these interactions is whether or not the changes in fiscal policy are expected to be permanent or transitory. To the extent that fiscal adjustments are perceived to be permanent, and are on the supply side, a standard neokeynesian model implies that spending cuts are less recessionary than tax hikes.

What can the Austrian economics add by way of interpretation and/or clarification? Generally, most of the results and theses of the book are by and large consistent with Austrian insights regarding the effects of public spending and taxation. According to the Keynesian tradition, an increase in the public deficit is assumed to increase total demand and thus to encourage producers to increase their production. But, an increase in the public deficit, cannot increase total demand; it only changes the structure of savings and investment and the structure of production.

Those who favor more government expenditures in the face of a public debt crisis (or oppose a reduction of such expenditures), in fact, suggest that the very same strategy that has led to the calamity would also be its solution. The emergence of a debt crisis by itself is 
evidence that the fiscal multiplier of public expenditure has not worked as promised. What is needed to overcome a debt crisis is a stimulus for private business through deregulation and tax reductions instead of more public spending.

ReCEIVED: February 152020.

ACCEPTED: FEBRUARY 272020. 